\title{
Dynamic Recrystallization Behavior of Austenite in Nb-bearing High Strength Low Alloy Steels and Stainless Steel ${ }^{*}$
}

\author{
By Chiaki OUCHI** and Tomoyoshi OKITA**
}

\section{Synopsis}

Dynamic recrystallization behavior of austenite in Nb-bearing HSLA steels as well as 18-8 stainless steel was investigated by hot compression testing. The hot deformation equipment, incorporating a rapid cooling system and an on-line data analysis system, made it possible to investigate the microstructural changes associated with the restoration process by fully suppressing the static recovery and recrystallization. The stress-strain behavior to a strain of 0.70 was investigated in the range of strain rate from $5 \times 10^{-4}$ to $10 \mathrm{~s}^{-1}$, and of temperature from 900 to $1200^{\circ} \mathrm{C}$. Dynamic recrystallization was observed in all the steels deformed under the condition of the Zener-Hollomon parameter being less than $10^{15} \mathrm{~s}^{-1}$, but it was not observed with the highest strain rate of $10 \mathrm{~s}^{-1}$. An increase of $\mathcal{N b}$ content in the HSLA steels increased the flow stress for any deformation condition and also increased the strain at onset of dynamic recrystallization. Dynamically recrystallized grain size was primarily related to the value of the Zener-Hollomon parameter, but was not infuenced by the initial grain size. The microstructural changes accompanying dynamic recovery and dynamic recrystallization were investigated by thin foil TEM observation and related to the results of hardness measurements.

\section{Introduction}

Microalloying elements such as $\mathrm{Nb}$ or $\mathrm{V}$ have been effectively utilized in high strength low alloy (HSLA) steels to produce general refinement of the transformed structure produced by controlled rolling practice. One of the primary effects of $\mathrm{Nb}$ is to retard static recrystallization of austenite between hot rolling passes, and it is therefore an important element of thermomechanical treatment.

On the other hand, in recent studies of hot deformation behavior, it has been pointed out that dynamic recrystallization of austenite can take place in carbon steels or HSLA steels. ${ }^{1-6)}$ In these studies dynamic recrystallization behavior has been investigated for the deformation condition of relatively lower strain rates below $10^{-1} \mathrm{~s}^{-1}$. But the strain rate involved in hot working processes such as the rolling of plate or strip mill is as high as $10 \mathrm{~s}^{-1}$. The dynamic restoration process during hot working is primarily influenced by crystal structure, stacking fault energy or alloying elements in addition to the hot working condition. ${ }^{2-7)}$ However, the effects of microalloying elements such as $\mathrm{Nb}$ on the dynamic restoration processes have not been investigated systematically, although it has been made clear that these microalloying elements influence the successive static recrystallization and grain growth behavior of austenite.

As is well known, the microstructure developed during hot deformation can change within a very short time after the deformation, particularly when the deformation is done at a very high strain rate. Because of this reason, most of the past investigations did not include or failed to observe the true microstructures of dynamic recovery or dynamic recrystallization. That is, the hot deformation equipment designed for investigation of the microstructural features in dynamic restoration process should have a rapid cooling system which enables the deformed structure to be quenched without a time delay after the deformation. The hot compression testing equipment with such a desirable cooling system was newly developed for the present studies. The hot deformation behavior of the HSLA steels as well as 18-8 stainless steel was studied by changing strain rate widely within the temperature range from 900 to $1200{ }^{\circ} \mathrm{C}$. The main objective was to investigate the effects of $\mathrm{Nb}$ and the initial austenite grain size on the dynamic restoration process and to clarify the microstructural changes accompanying dynamic recovery and dynamic recrystallization.

\section{Experimental Procedures}

\section{Experimental Equipment}

The hot compression testing equipment has a maximum load capacity of $2000 \mathrm{~kg}$ and strain rate can be varied from $4 \times 10^{-4}$ to $10 \mathrm{~s}^{-1}$. The cylindrical specimen, which is $8 \mathrm{~mm}$ in diameter and $12 \mathrm{~mm}$ in length, was heated by a high frequency induction coil in vacuum. The schematic representation of this testing equipment is given in Fig. 1. The hot compression testing was completely programmed. That is, the reheating and deformation temperatures, the holding time before and after deformation, and the cooling condition were all previously set. The most elaborate and important component of this equipment is the system for post-deformation cooling of the specimen. The deformed specimen is quenched after a post-deformation time delay of less than $0.01 \mathrm{~s}$, and the average rapid cooling rate of around $500{ }^{\circ} \mathrm{C} / \mathrm{s}$ is attained by $\mathrm{He}$ gas quenching. This cooling ability is needed to avoid the progress of static recrystallization and thereby observe the dynamical microstructural changes developed during hot deformation. The load and displacement data were recorded and processed by an on-line microcomputer to provide true stress-strain curve on a plotter. The maximum compressive true strain used in this study was 0.70 .

* Presented to the 91st ISIJ Meeting, April 1976, at The University of Tokyo in Tokyo. Manuscript received May 14, 1981. (C) 1982 ISIJ

** Steel Products Laboratory, Technical Research Center, Nippon Kokan K.K., Minamiwatarida-cho, Kawasaki-ku, Kawasaki 210. 
Barrelling of the specimen due to friction was minimized by very refined grinding of the specimen and silica die contact surfaces.

\section{Materials and Experimental Procedures}

The chemical compositions of the $0.10 \% \mathrm{C}-1.50$ $\% \mathrm{Mn}$ steels used are listed in Table 1. The Nb contents were varied up to $0.12 \%$. A steel containing a small amount of Ti was prepared in order to examine the effect of the initial grain size on the dynamic recrystallization behavior, TiN precipitates producing a refinement of the austenite grain size at the higher reheating temperatures. The 18-8 stainless steel was included as a representative austenitic material which allows observation of the substructure developed during the dynamic restoration process. The steels were melted in a $150 \mathrm{~kg}$ induction heating furnace. Ingots were hot-rolled to $12 \mathrm{~mm}$ thickness and the compression specimens were prepared from the plates. The specimen was reheated at $1250^{\circ} \mathrm{C}$ for $10 \mathrm{~min}$ if not otherwise stated, and cooled within $30 \mathrm{~s}$ to the deformation temperature ranging from 900 to $1200{ }^{\circ} \mathrm{C}$. After holding for $1 \mathrm{~min}$ at the deformation temperature, the deformation was performed at various strain rates from $5.0 \times 10^{-4}$ to $10.3 \mathrm{~s}^{-1}$. Following the He gas quenching, the deformed specimens were halved by cutting parallel to the loading direction, and the austenitic grain boundaries on the polished sections of the HSLA steels and the stainless

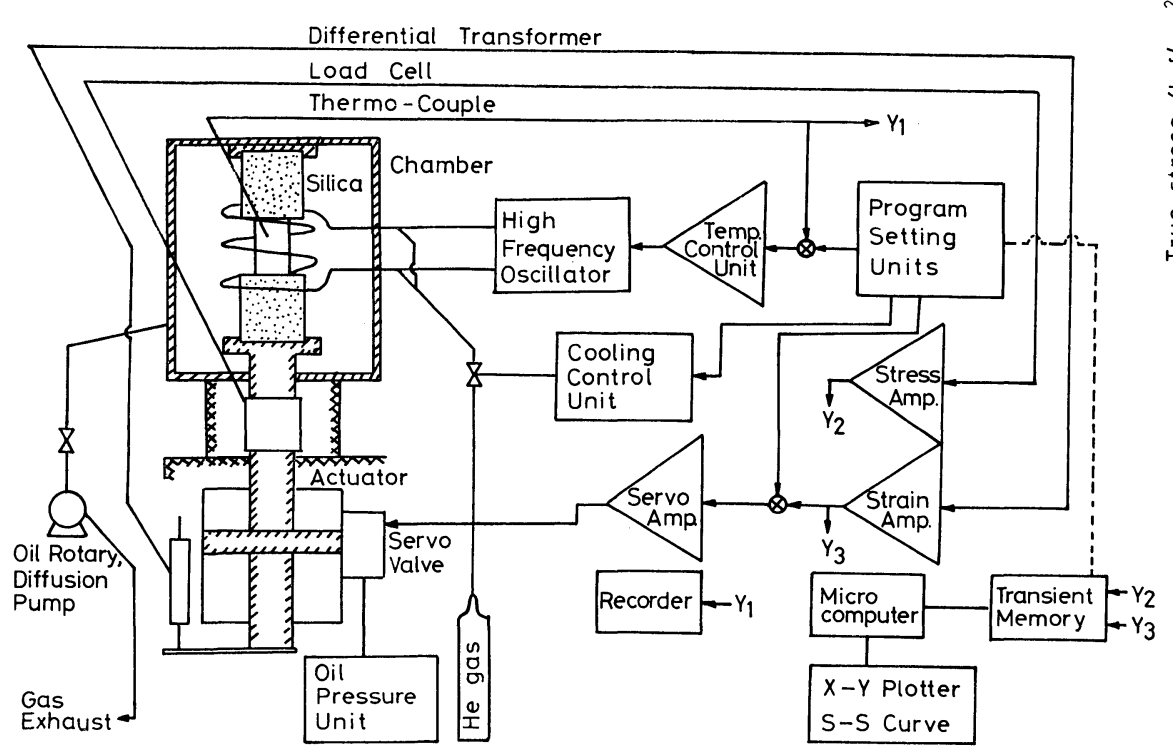

Fig. 1. Schematic representation of hot deformation equipment. steel were revealed by etching in a aqueous solution of picric acid and by electrolytic etching in nitric acid, respectively.

\section{Results}

\section{The Effects of Temperature and Strain Rate on Hot Deformation Behavior}

The stress-strain (S-S) behavior of the curves was investigated for various combinations of the temperature and strain rate. Figure 2 shows examples of the $\mathrm{S}-\mathrm{S}$ curves in the $\mathrm{Si}-\mathrm{Mn}$ and Nb-bearing steels. When the specimen was deformed to the strain of 0.70 , two types of S-S curves were observed, depending on the temperature and strain rate. The first one exhibited only continuous work hardening, and the second one was characterized by peak stress $\left(\sigma_{p}\right)$ followed by the steady state flow stress $\left(\sigma_{s}\right)$. Dynamic recrystallization was accounted for the latter type of S-S curve and took place during deformation at temperatures above $1000^{\circ} \mathrm{C}$ with the strain rate less than $10^{-1} \mathrm{~s}^{-1}$. $\mathrm{Nb}$ increased the flow stress in proportion to its content in the both types of S-S curves. ${ }^{6}{ }^{6}$

The changes of the peak stress $\left(\sigma_{p}\right)$ and the strain

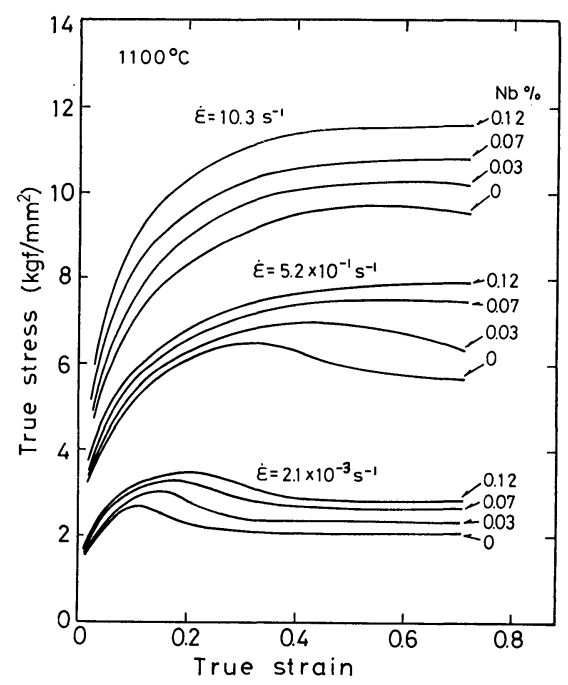

Reheated at $1250^{\circ} \mathrm{C}$

Deformed at $1100^{\circ} \mathrm{C}$

Initial austenitic grain size: $0 \% \mathrm{Nb}: 360 \mu \mathrm{m}$

$0.03 \% \mathrm{Nb}: 270 \mu \mathrm{m}$ $0.07 \% \mathrm{Nb}: 230 \mu \mathrm{m}$

$0.12 \% \mathrm{Nb}: 195 \mu \mathrm{m}$

Fig. 2. Effect of $\mathrm{Nb}$ on stress-strain curves.

Table 1. Chemical compositions of steels used.

\begin{tabular}{|c|c|c|c|c|c|c|c|c|c|c|c|c|}
\hline Steel & $\mathrm{G}$ & $\mathrm{Si}$ & $\mathrm{Mn}$ & $P$ & $\mathrm{~S}$ & $\mathrm{Ni}$ & $\mathrm{Cr}$ & Mo & $\mathrm{Nb}$ & $\mathrm{Ti}$ & sol. Al & $\mathrm{N}$ \\
\hline $\mathrm{Si}-\mathrm{Mn}$ & 0.10 & 0.22 & 1.50 & 0.015 & 0.010 & - & - & - & - & - & 0.023 & 0.0069 \\
\hline $0.03 \mathrm{Nb}$ & 0.09 & 0.22 & 1.54 & 0.016 & 0.010 & - & - & - & 0.032 & - & 0.027 & 0.0066 \\
\hline $0.07 \mathrm{Nb}$ & 0.09 & 0.27 & 1.51 & 0.015 & 0.010 & - & - & - & 0.072 & - & 0.034 & 0.0051 \\
\hline $0.12 \mathrm{Nb}$ & 0.09 & 0.26 & 1.55 & 0.015 & 0.008 & - & - & - & 0.124 & - & 0.029 & 0.0061 \\
\hline $\mathrm{Ti}$ & 0.12 & 0.22 & 1.32 & 0.018 & 0.004 & - & - & 0.13 & 0.036 & 0.017 & 0.020 & 0.0058 \\
\hline 18-8 stainless & 0.06 & 0.75 & 1.56 & 0.031 & 0.008 & 9.07 & 18.70 & 0.22 & & & 0.025 & 0.0271 \\
\hline
\end{tabular}


at the peak stress $\left(\varepsilon_{p}\right)$ with $\mathrm{Nb}$ content, temperature and strain rate are summarized in Fig. 3. The increase of $\mathrm{Nb}$ content increased both $\sigma_{p}$ and $\varepsilon_{p}$. This effect of $\mathrm{Nb}$ was not significantly influenced by the deformation temperature and strain rate. The decrease of the deformation temperature and the increase of strain rate resulted in the increase of $\sigma_{p}$ and $\varepsilon_{p}$, similar to the effect of the increase of $\mathrm{Nb}$ content.

The S-S curves of 18-8 stainless steel are given in Fig. 4 (compared with the HSLA steels.) This steel showed a relatively higher flow stress as well as a higher work hardening rate under the deformation condition of higher strain rate or lower temperature. Stress-strain curves distorted by dynamic recrystallization were observed during deformation at higher temperatures and slower strain rates. ${ }^{8)}$ In these cases larger strain differences $\left(\varepsilon_{s}-\varepsilon_{p}\right)$ as well as smaller flow stress differences $\left(\sigma_{p}-\sigma_{s}\right)$ were observed, where $\sigma_{s}$ and $\varepsilon_{s}$ are flow stress and onset strain of steady state flow, respectively. The strain difference $\left(\varepsilon_{s}-\varepsilon_{p}\right)$ is an indication of the progress of dynamic recrystallization, and

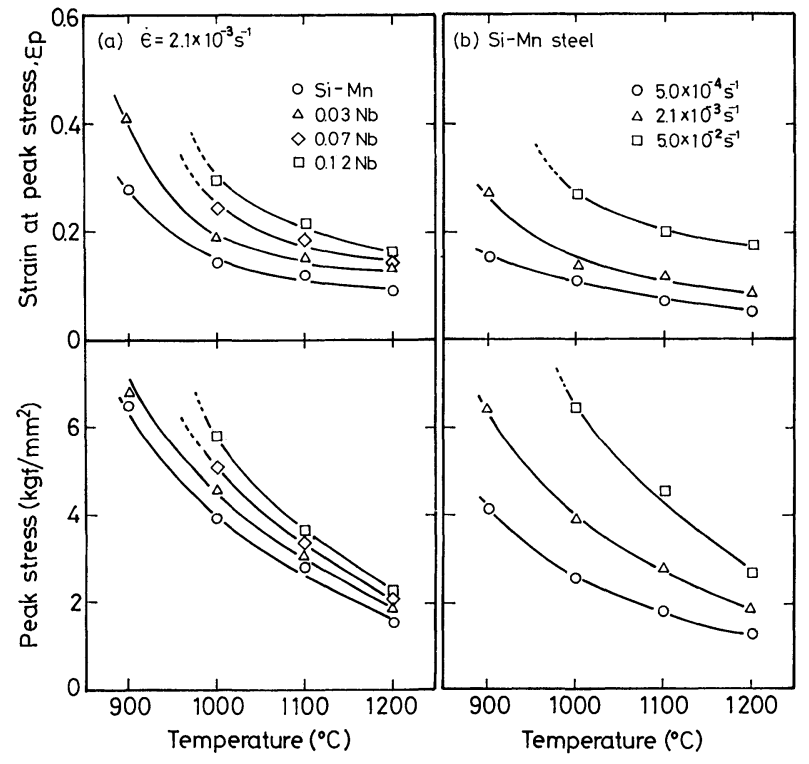

Fig. 3. Effect of deformation temperature, strain rate and $\mathrm{Nb}$ content on peak stress $\left(\sigma_{p}\right)$ and strain at peak stress $\left(\varepsilon_{p}\right)$.

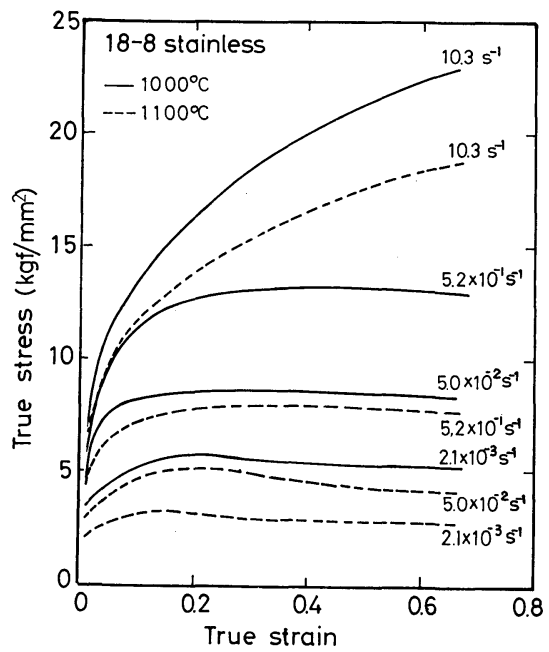

Fig. 4. Stress-strain curves of 18-8 stainless steel. the higher alloying content of $\mathrm{Ni}$ and $\mathrm{Cr}$ in this steel appears to retard this progress of recrystallization. A similar retardation tendency was observed in the higher Nb-bearing steels as shown in Fig. 2.

The prominent dependence of the flow stress on the temperature and strain rate suggests that the hot deformation process is controlled by a thermally activated process, and the relation between these parameters is expressed by the following equations. ${ }^{1)}$

$$
\begin{aligned}
& \dot{\varepsilon}=A \sigma^{m} \exp (-Q / R T) \\
& \dot{\varepsilon}=A^{\prime}\{\sin h(\alpha \sigma)\}^{n} \exp (-Q / R T)
\end{aligned}
$$

where $A, A^{\prime}, \alpha, m$ and $n$ are independent of constant, $Q$ is an activation energy, $R$ is the gas constant, and $\mathcal{T}$ is the absolute temperature. From Eq. (1) $Q$ is given as:

$$
Q=-R\left(\frac{\partial \ln \dot{\varepsilon}}{\partial 1 / T}\right)_{\sigma}
$$

The values of $Q$ obtained at a constant value of the peak stress for each steel are summarized in Table 2. A small range of values around 94 97 kcal $/ \mathrm{mol}$ was obtained for all the steels, and these values were higher than the activation energy of the $65 \sim 75 \mathrm{kcal} / \mathrm{mol}^{1,2,5)}$ for self-diffusion of iron in austenite.

The Zener-Hollomon parameter, which is the strain rate compensated by the temperature, is expressed as follows ${ }^{1,2,6)}$ :

$$
Z=\dot{\varepsilon} \exp (Q / R T)=A \sigma^{m}
$$

or

$$
Z=\dot{\varepsilon} \exp (Q / R T)=A^{\prime}\{\sin h(\alpha \sigma)\}^{n}
$$

Table 2. Activation energy $Q$ and stress exponent of $m$ and $n$.

\begin{tabular}{l|c|cc}
\hline \multicolumn{1}{c|}{ Steel } & $\begin{array}{c}\text { Activation } \\
\text { energy } Q\end{array}$ & \multicolumn{2}{|c}{ Stress exponent } \\
\cline { 3 - 4 }$(\mathrm{kcal} / \mathrm{mol})$ & $m$ & $n$ \\
\hline $\mathrm{Si}-\mathrm{Mn}$ & 97 & 5.7 & 4.8 \\
$0.03 \mathrm{Nb}$ & 96 & 6.1 & 5.3 \\
$18-8$ stainless & 94 & 4.9 & 4.4 \\
\hline
\end{tabular}

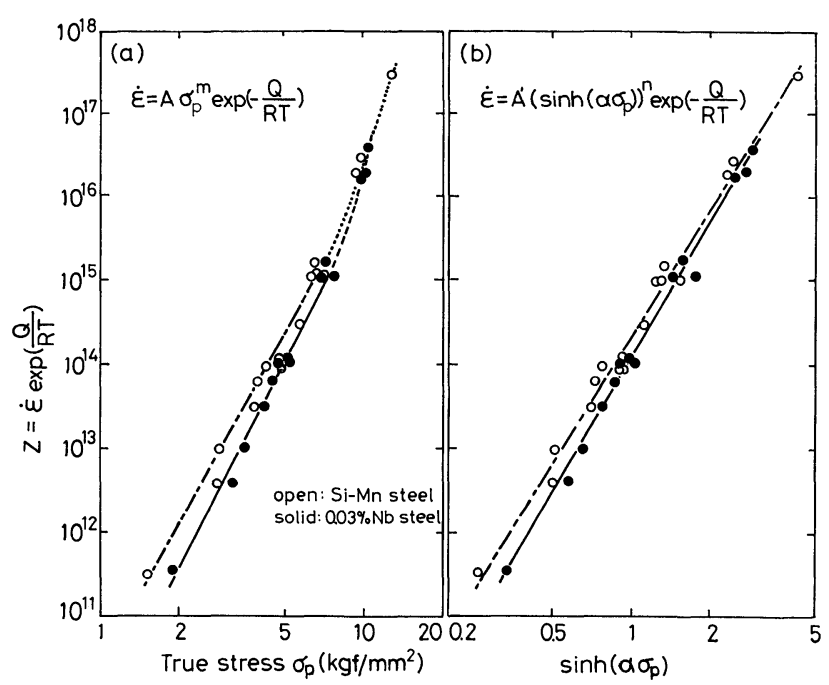

Fig. 5. Relation of $Z$ parameter and peak stress in $\mathrm{Si}-\mathrm{Mn}$ steel and $0.03 \% \mathrm{Nb}$ steel. 
The relation of $Z$ and $\sigma_{p}$ based on these equations are shown graphically in Fig. 5 . While the experimental data deviate from agreement with Eq. (4) at peak stresses above $7 \mathrm{kgf} / \mathrm{mm}^{2}$, the agreement with Eq. (5) was more extensive. Compared with the SiMn steel, the Nb-bearing steel has a higher stress for the same $Z$ value. The values of $m$ and $n$ obtained from these figures together with those for the 18-8 stainless steel are given in Table 2. It has been reported that for metals in which the dynamic restoration processes are those of dynamic recovery or dynamic recrystallization, the $m$ value is around $4 \sim 5$ or above 6, respectively. ${ }^{9-11)}$ On this basis the austenite of the HSLA steels can be classified as a metal of the dynamic recrystallization type. Although the 18-8 stainless steel showed a relatively low $m$ value, it was confirmed from the microstructural observation that this steel also belonged to the dynamic recrystallization class.

\section{Observation of Microstructure}

Photograph 1 shows the progress of the static recrystallization with time following the deformation at the highest strain rate of $10.3 \mathrm{~s}^{-1}$. It clearly proceeds very rapidly within a holding time of less than $1 \mathrm{~s}$. This result also indicates that the quenching capacity of the newly-developed cooling system is more than adequate for investigation of microstructural changes
$0.03 \% \mathrm{Nb}$ steel

Deformed at $1000^{\circ} \mathrm{C}$

Strain rate: $10.3 \mathrm{~s}^{-1}$

Strain: 0.4

Holding time:

Photo. 1.

Progress of static recrystallization.

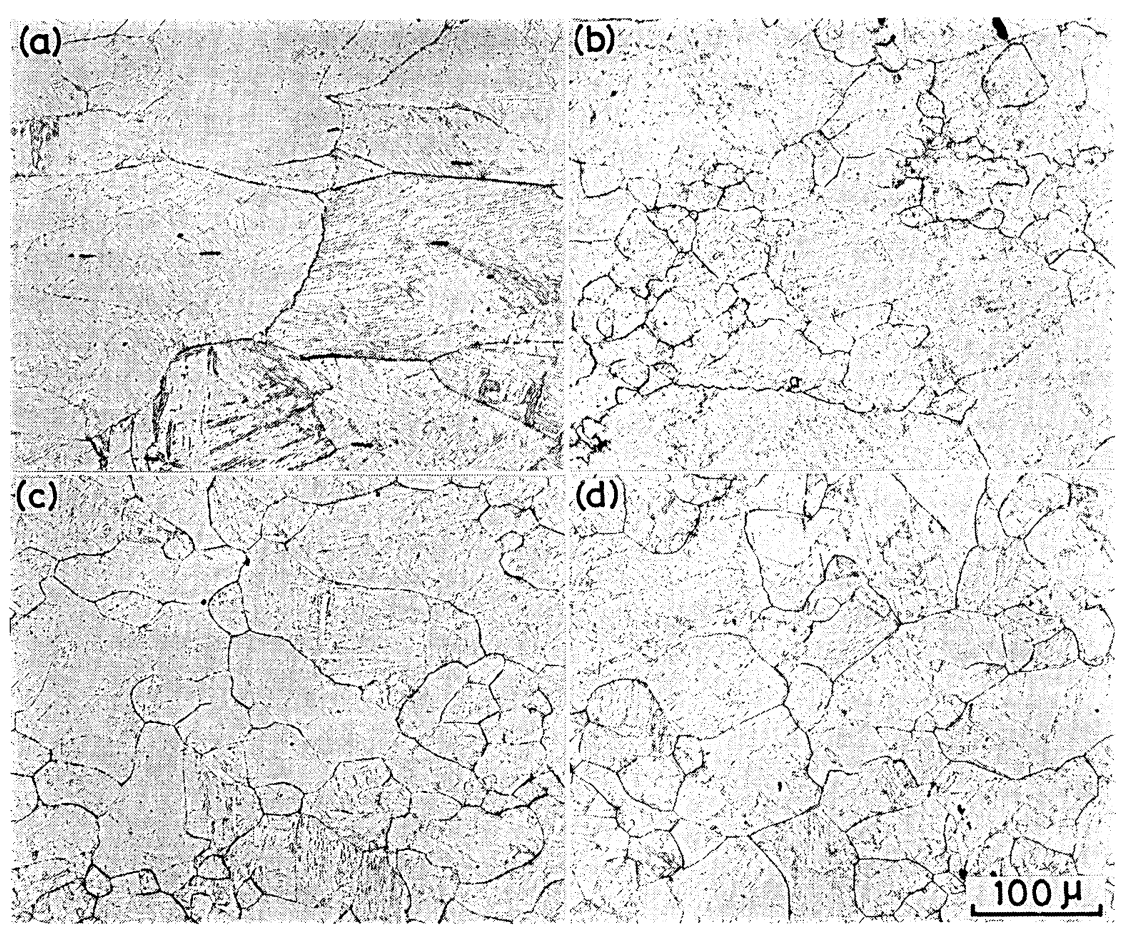

$0.03 \% \mathrm{Nb}$ steel

Deformed at $1100^{\circ} \mathrm{C}$

Strain rate: $5.0 \times 10^{-2} \mathrm{~s}^{-1}$

Strain: (a) $0.14 \quad$ (b) 0.23

$\begin{array}{ll}\text { (c) } 0.42 & \text { (d) } 0.70\end{array}$

Photo. 2.

Progress of dynamic recrystallization with strain. 
developed during dynamic restoration process. The progress of dynamic recrystallization with strain shown in Photo. 2 was investigated by interruption of deformation at the strains indicated on the S-S curve shown. Dynamic recrystallization started at a strain of approximately $0.8 \times \varepsilon_{p}$ and it originated from the local bulging of austenitic grain boundary (Photo. 2(a)). At the strain for peak stress, the recrystallized grains were formed along the austenitic grain boundary and grew into the original grain matrix with increasing strain. In the steady state period, the original grain boundaries could no longer be recognized, and newly formed grains with irregular boundaries $^{5)}$ filled the whole of the microstructure. These structural changes during deformation were the same in steels with and without $\mathrm{Nb}$.
The deformed microstructure of the 18-8 stainless steel exhibited in Photo. 3, was investigated at a given strain of 0.70 for different strain rates at $1000^{\circ} \mathrm{C}$. While the original grains were simply deformed to a pancake shape at the highest strain rate of $10.3 \mathrm{~s}^{-1}$, but at the intermediate strain rate of $5.2 \times 10^{-1} \mathrm{~s}^{-1}$ dynamically recrystallized grains were nucleated at the original grain boundaries and the deformation bands. At the low strain rate of $2.1 \times 10^{-3} \mathrm{~s}^{-1}$ an almost completely recrystallized grain structure was formed. The substructures developed at each level of deformation rate are shown in Photo. 4. A well-defined cell structure was formed at the highest strain rate (Photo. 4(a)) and was recovered dynamically with decreasing strain rate. The dynamically recrystallized grain structure produced at the slower strain rate (Photos.

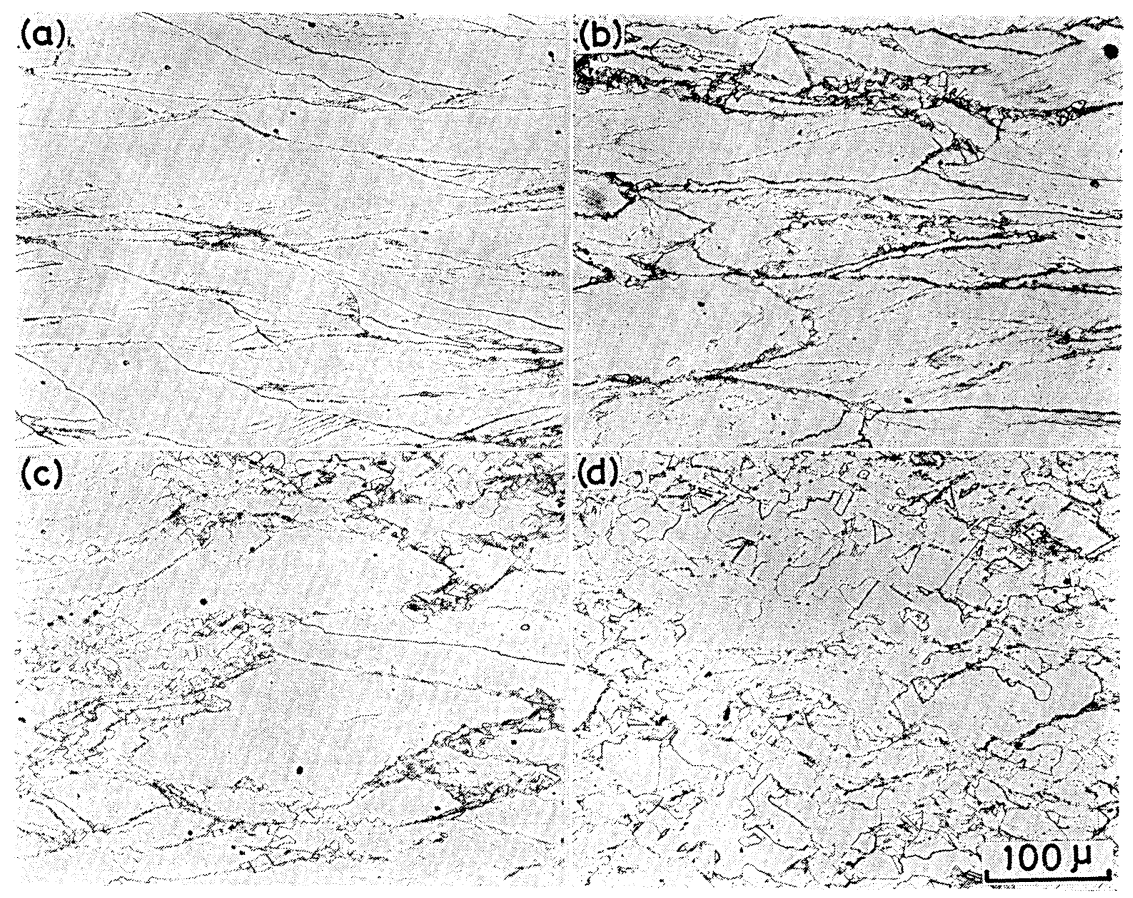

Deformed at $1000{ }^{\circ} \mathrm{C}$

Strain rate: (a) $10.3 \mathrm{~s}^{-1}$

(b) $5.2 \times 10^{-1} \mathrm{~s}^{-1}$

(c) $5.0 \times 10^{-2} \mathrm{~s}^{-1}$

Strain: 0170

(d) $2.1 \times 10^{-3} \mathrm{~s}^{-1}$

Photo. 3.

Microstructural changes with strain rate in 18-8 stainless steel.

Deformed at $1000{ }^{\circ} \mathrm{C}$

Strain rate: (a) $10.3 \mathrm{~s}^{-1}$

(b) $5.2 \times 10^{-1} \mathrm{~s}^{-1}$

(c) $5.0 \times 10^{-2} \mathrm{~s}^{-1}$

(d) $2.1 \times 10^{-3} \mathrm{~s}^{-1}$

Photo. 4.

Thin foil electron micrographs of $18-8$ stainless steel.
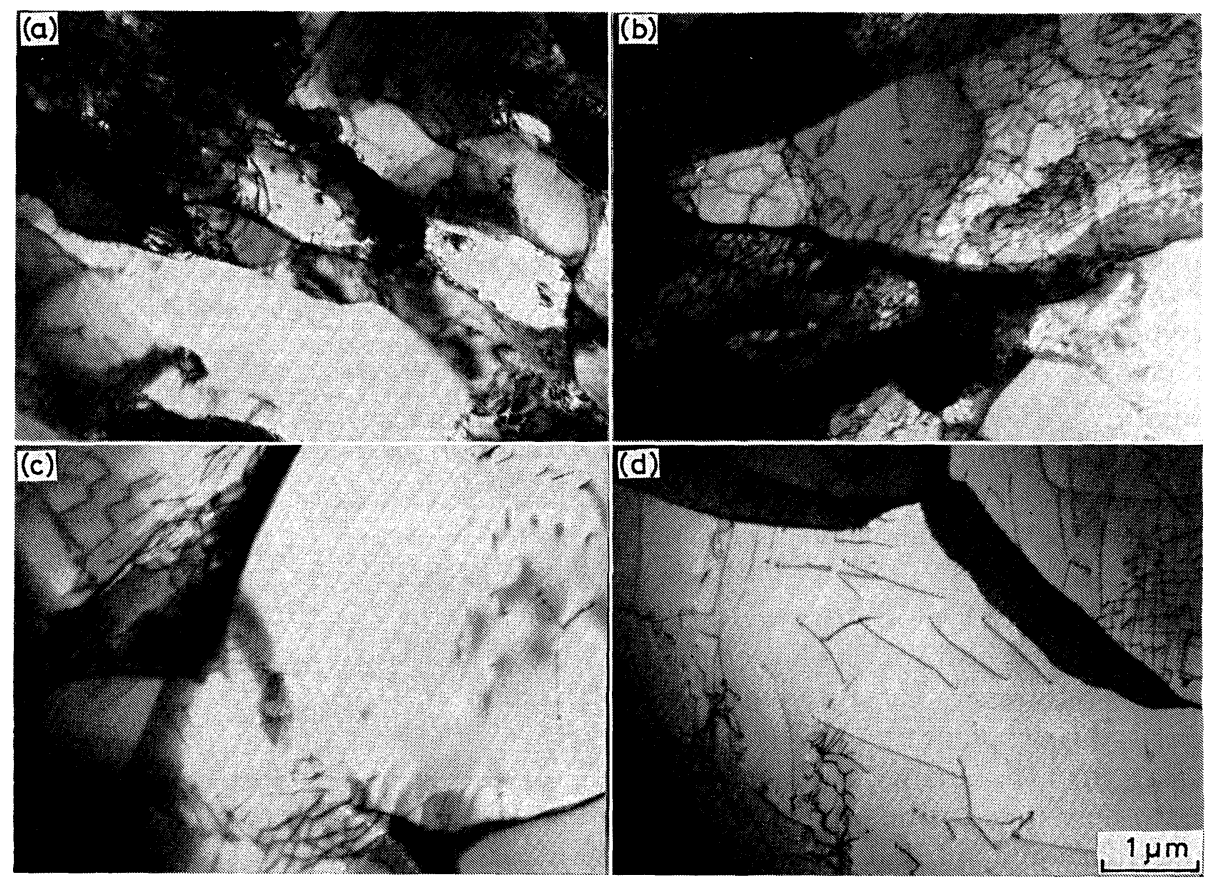
4(c) and (d)) contained isolated or network-like dislocations inside the grains. Contrasting with this, the statically recrystallized grains contained twin boundaries and very few dislocations. That is, the substructures observed in the dynamically recrystallized grain appeared to be formed during hot deformation. The irregular shaped grain boundaries and the substructure without formation of twin boundary in dynamic recrystallization are a major microstructural difference from static recrystallization. ${ }^{12-14)}$

\section{Effect of Initial Grain Size}

The initial austenitic grain size strongly influences the static recrystallization behavior after hot deformation, a finer initial grain size increases the rate of static recrystallization and gives rise to a finer recrystallized grain structure. The effects of the initial grain size on dynamic restoration behavior were investigated in the HSLA steels, including $0.03 \% \mathrm{Nb-}$ $0.02 \% \mathrm{Ti}$ steel. The initial grain size was varied by changing the reheating temperatures between $1250^{\circ} \mathrm{C}$ and $1000^{\circ} \mathrm{G}$. For the $\mathrm{Nb}-\mathrm{Ti}$ steel a very fine grain size of $67 \mu \mathrm{m}$ was obtained at the reheating temperature of $1250^{\circ} \mathrm{C}$. Figure 6 shows the effect of the initial grain size on the $\mathrm{S}-\mathrm{S}$ curve behavior in the $\mathrm{Si}-$ Mn steel. Refinement of the initial grain size increased the flow stress especially at the higher strain rate, and reduced $\varepsilon_{p}$ at the lower strain rate. Although refinement of the initial grain size tended to give rise to dynamic recrystallization for deformation conditions corresponding to relatively high $Z$ values under a given strain of 0.70 , the deformation at $10.3 \mathrm{~s}^{-1}$ never caused the steady state flows of dynamic recrystallization even in the finest initial grain size of $29 \mu \mathrm{m}$.

The relation of the initial grain size and the dynamically recrystallized grain size is given in Figs. 7 and 8. Figure 7 shows that the recrystallized grain size depends closely on the steady state flow stress, but not on the initial grain size. ${ }^{17)}$ Figure 8 makes clear again that the recrystallized grain size is primarily controlled by the combination of temperature and strain rate. Thus the deformation conditions corresponding to higher $Z$ values and therefore the higher stress gave rise to the finer recrystallized grain.

As shown in Fig. 6, the S-S curves for the case of dynamic recrystallization changed from the steady state flow type with one peak stress to the cyclic type repeating the work hardening and softening with the smaller initial grain size. In Fig. 8, the S-S curves associated with dynamic recrystallization are classified as the steady state flow type or the oscillatory type. Several explanations have been proposed for both types of the S-S curves, ${ }^{5,13,15,16)}$ one of which is that the oscillatory type S-S curve is produced when the recrystallized grain size is larger than the initial grain size. ${ }^{5)}$ However, the result of Fig. 8 does not support this explanation. The present results make clear that the change of the S-S curve from steady state flow type to the oscillatory type is related to the deformation condition accompanied with a reduction

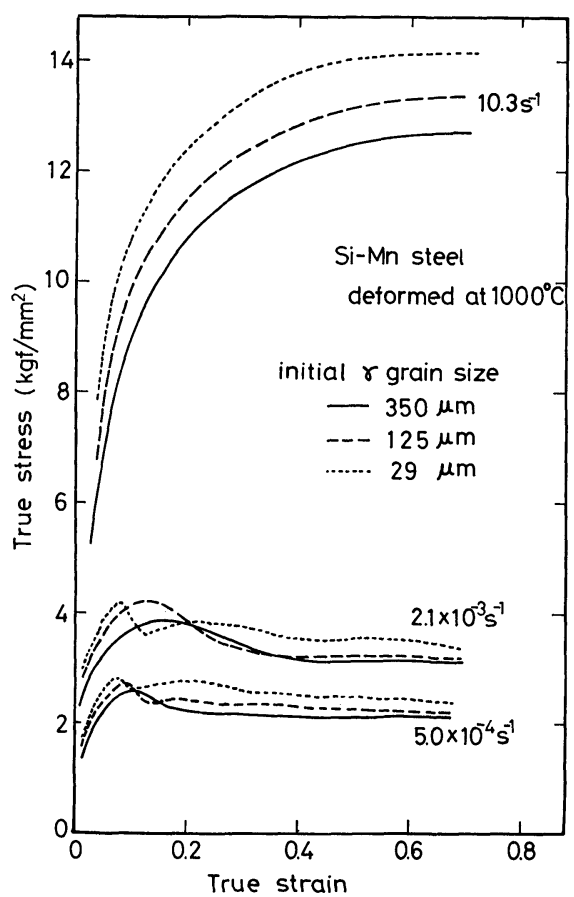

Fig. 6. Effect of initial austenitic grain size on stressstrain behavior in $\mathrm{Si}-\mathrm{Mn}$ steel; deformed at $1000^{\circ} \mathrm{C}$.

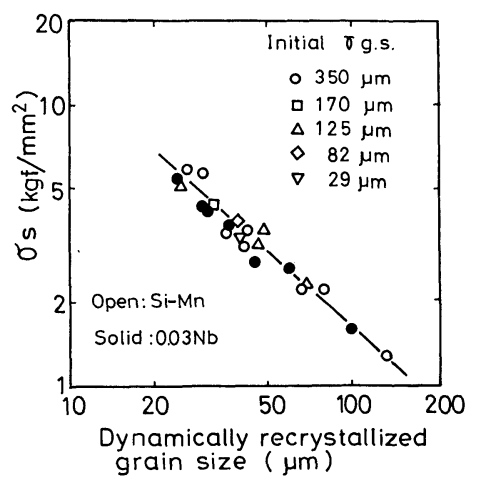

Fig. 7. Relation of dynamically recrystallized grain size and steady state flow stress $\left(\sigma_{s}\right)$.

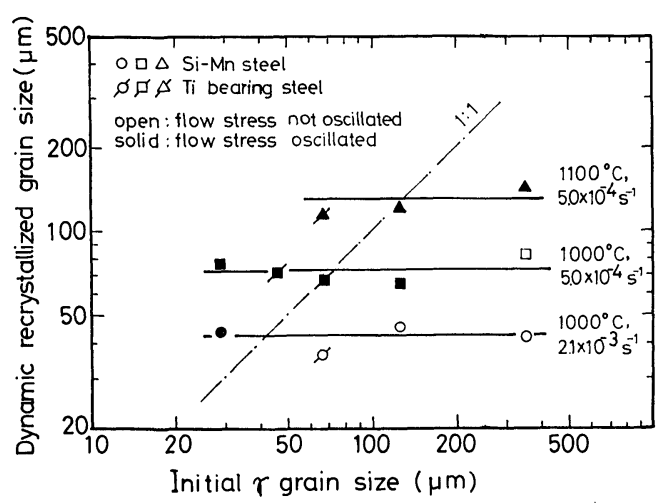

Fig. 8. Relation of initial austenitic grain size and dynamically recrystallized grain size.

of the $Z$ value under a given initial grain size or by refinement of the initial grain size under a given deformation condition. Refinement of the initial grain size simply increases the nucleation site area for 
dynamic recrystallization. This may give rise to an abrupt reduction of stress less than the level of the steady state flow stress, and then a second work hardening period can take place from certain stress. This would be repeated until the equilibrium microstructure determined by the deformation condition is attained.

\section{Discussion}

\section{The Effects of $\mathrm{Nb}$ and the Initial $\gamma$ Grain Size on Dynamic Recrystallization}

It was made clear from this study that $\mathrm{Nb}$ addition into the HSLA steels retarded dynamic recrystallization in the same way that it retarded static recrystallization. Although these results are consistent with those of previous reports, two different mechanisms for this have been previously proposed. ${ }^{18-21)}$

One is based on the solute drag effect due to $\mathrm{Nb}$ atoms, ${ }^{19,21)}$ and the other is attributed to strain induced or dynamic precipitation of $\mathrm{Nb}(\mathrm{CN}) .{ }^{18,20)}$ With regard to this point, the additional experiments were carried out. The results of Figs. 2 and 3 were obtained with the same reheating temperature of $1250^{\circ} \mathrm{C}$, and this caused a different initial austenite grain size among the steels as well as a variation in the solution of $\mathrm{Nb}$. As an alternative procedure the dynamic recrystallization behavior was investigated by varying the reheating temperatures from $1230^{\circ} \mathrm{G}$ in the $\mathrm{Nb}$-free steel to $1320^{\circ} \mathrm{C}$ in $0.12 \% \mathrm{Nb}$ steel, which resulted in the almost the same initial $\gamma$ grain size of around $320 \mu \mathrm{m}$ and the complete dissolution of $\mathrm{Nb}(\mathrm{CN})$ in $\gamma$ in all the steels.

Figure 9 shows this result where the change of the peak strain with the strain rate was given for the case of the deformation at $1100{ }^{\circ} \mathrm{C}$. The increase of $\mathrm{Nb}$ content increased the peak strain, particularly at the higher strain rate. The deformation time period at strain rates above $10^{-1} \mathrm{~s}^{-1}$ is considered to be short enough to avoid dynamic precipitation of $\mathrm{Nb}(\mathrm{CN})$ in austenite. The second experiment involved varying the reheating temperatures from 1250 to $950^{\circ} \mathrm{C}$ with a fixed deformation temperature of $950^{\circ} \mathrm{C}$ and a strain rate of $2.1 \times 10^{-3} \mathrm{~s}^{-1}$. This thermal history caused the continuous variation of the initial $\gamma$ grain size and $\mathrm{Nb}$ content dissolved in $\gamma$. This result is illustrated in Fig. 10 where the relation of the initial grain size and the peak strain is shown. The Nb-free steel showed a relatively small dependence of peak strain on the initial grain size. $\varepsilon_{p}$ increased with $\mathrm{Nb}$ content at the higher reheating temperatures which increased the $\mathrm{Nb}$ content dissolved in $\gamma$, and the reheating temperature of $950^{\circ} \mathrm{C}$ brought about very small difference of $\varepsilon_{p}$ among the steels. On reheating at $950{ }^{\circ} \mathrm{C}$ in the Nb-bearing steels, most of the $\mathrm{Nb}(\mathrm{CN})$ precipitates remain undissolved, and these dispersed and relatively coarse precipitates did not affect dynamic recrystallization behavior.

All the above results indicate that $\mathrm{Nb}$ dissolved at the reheating temperature retards the onset of dynamic recrystallization. The $\mathrm{Nb}$ atom or its clustering will retard the annihilation or re-arrangement of disloca-

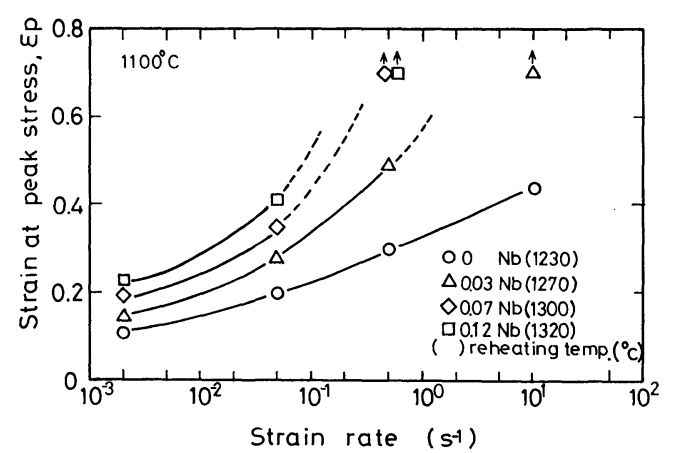

Initial austenitic grain sizes of various steels: around $320 \mu \mathrm{m}$

Fig. 9. Effect of strain rate on strain at peak stress in HSLA steels.

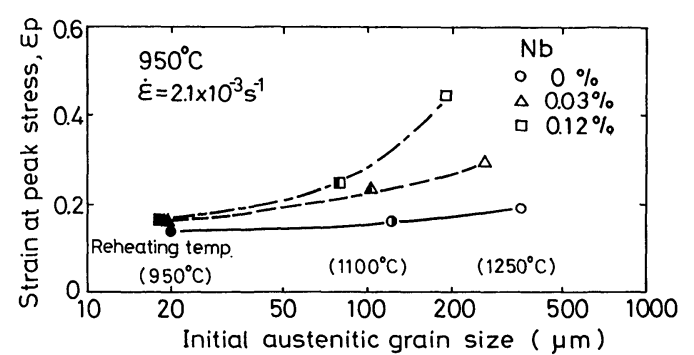

Fig. 10. Effect of initial austenitic grain size on peak strain in stress-strain curves of dynamic recrystallization.

tions introduced during deformation, and this increases the strain for the onset of the local grain boundary bulging. One of the present authors confirmed these effects of solute $\mathrm{Nb}$ through studies of $\mathrm{Nb}$ steels containing ultra-low amounts of $\mathrm{C}$ and $\mathrm{N}$, and therefore no $\mathrm{Nb}(\mathrm{CN})$ precipitates. ${ }^{22)}$ The dissolved $\mathrm{Nb}$ retarded not only the onset of dynamic recrystallization but also the onset of the static recrystallization, and these solute $\mathrm{Nb}$ effects appeared to be caused primarily by the size effect of the $\mathrm{Nb}$ atom, although another explanation based on the number of electron in outer shell solute atom has been proposed. ${ }^{23)}$

It has been reported that dynamic precipitation of $\mathrm{Nb}(\mathrm{CN})$ took place concurrently with dynamic recrystallization in the $\mathrm{Nb}$ steel. ${ }^{20}$ ) It was found, however, that these $\mathrm{Nb}(\mathrm{CN})$ precipitates hardly influence the dynamically recrystallized grain size, which was controlled primarily by the flow stress as shown in Fig. 7 . This indicates that the new grain boundaries would be repeatedly forming and migrating without the influence of the $\mathrm{Nb}(\mathrm{CN})$ precipitates, once the steady state flow of dynamic recrystallization is attained. The $\mathrm{Nb}(\mathrm{CN})$ precipitates formed during hot deformation at the slower strain rate will become too coarse to inhibit the grain boundary migration. Authors have investigated the austenitic grain growth behavior after static and dynamic recrystallization in steels similar to those investigated here. For the case of the $\mathrm{Nb}$ steel, the dynamically recrystallized grain structure caused a much more rapid subsequent grain growth at $1100^{\circ} \mathrm{C}$ compared with grain growth 
after static recrystallization. Although a detailed discussion of this investigation is to be given in a separate paper, ${ }^{24)}$ this difference of grain growth behavior after hot deformation in the $\mathrm{Nb}$ steel appears to be mainly based on the size difference of $\mathrm{Nb}(\mathrm{CN})$ precipitates in both types of recrystallization.

\section{The Structure of Dynamically Recrystallized Grains}

The present study clearly indicates that dynamic recrystallization is caused by local grain boundary bulging at several points along the grain boundary in an early stage of nucleation. A similar nucleation mechanism was observed in the static recrystallization of austenite after hot working. ${ }^{25)}$ Dynamically recrystallized microstructure contained substructure in the grain matrix as well as irregular-shaped grain boundaries. The substructure observed in 18-8 stainless steel consisted of dislocation networks with a relatively lower dislocation density, but this was quite different from the substructure of dynamically recrystallized copper in which case a much higher dislocation density was observed. ${ }^{26)}$ To confirm this point, hardness measurements at room temperature were carried out in 18-8 stainless steel specimens quenched after hot deformation. Figure 11 shows the relation of hardness to the $Z$ value, which corresponds to the various combinations of the temperature and strain rate under a given strain of 0.70 . In this figure, dynamic recovery or dynamic recrystallization was classified on the basis of whether the strain of 0.70 was below $\varepsilon_{p} \times 0.8$ or it reached into the steady state flow region. The dynamically recovered structure gave rise to Vickers hardness values above 220 and the dynamically recrystallized structure showed hardness values in the range 140 to 170 . The statically recrystallized grain structure was obtained by holding at $1000^{\circ} \mathrm{C}$ for $10 \mathrm{~min}$ after straining at $1000^{\circ} \mathrm{C}$ at a strain rate of $10 \mathrm{~s}^{-1}$. The difference in hardness for statically and dynamically recrystallized grain structures was very small. The hardness value of the 18-8 stainless steel obtained by cold rolling with a total reduction of $50 \%$ was 370 . Using this value and the hardness of the statically recrystallized condition, fractional softening due to dynamic restoration process was estimated and is given in the upper half of Fig. 11. It is evident that the softening ratio of dynamic recovery and dynamic recrystallization was more than $60 \%$ and $90 \%$, respectively. It can be understood from this result that the substructure developed due to the dynamic restoration process consists of a much lower dislocation density compared to that of cold rolling. As shown in Fig. 5, the hot deformation condition with the lower $Z$ value caused the lower flow stress, and this flow stress maintains the balance of the microstructural change produced during hot deformation. As the hot deformation condition favoring of dynamic recrystallization is in the direction of lower strain rate and higher temperature, that is lower $Z$ value, dynamically recrystallized microstructure results in the very soft hardness compared with that of dynamic recovery under the given strain deformation.

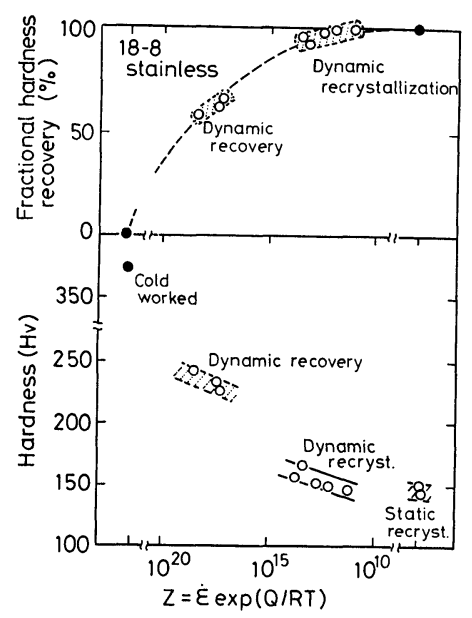

18-8 stainless steel

Load in Vickers Hardness test: $1 \mathrm{~kg}$

Austenitic grain size of static recrystallization structure: around $25 \mu \mathrm{m}$

Fig. 11. Relation of $Z$ parameter and room temperature hardness.

It can be inferred that the similar substructure of dynamic recovery and recrystallization would be formed also in the HSLA steels. The flow stress of the HSLA steels was increased by a $\mathrm{Nb}$ addition for any deformation condition, and this was presumably caused by solute $\mathrm{Nb}$ or by dynamic precipitation of $\mathrm{Nb}(\mathrm{CN})$ at high strain rates and slow strain rates, respectively. Both the HSLA steels and the stainless steel exhibited very similar hot deformation behavior, although the latter steel showed the relatively higher flow stress and the higher onset strain of dynamic recrystallization due to its higher alloying of $\mathrm{Ni}$ and Cr.

With regard to the possibility of dynamic recrystallization occurring in the hot rolling process or the high strain rate deformation process, the results of the several past studies have been confusing. ${ }^{11,27)}$ Certainly dynamic recrystallization can be investigated through both plastic flow behavior and observation of the quenched microstructure. In practice the hot rolling processes such as plate or strip mill involve strain rates above $10 \mathrm{~s}^{-1}$ and a rolling pass strain less than 0.4. The present results shown in Figs. 2 to 4 indicate that dynamic recrystallization is unlikely to occur under these hot deformation conditions. The present results also demonstrate that the availability of an experimental technique for quenching the microstructure developed during hot deformation is extremely important. This is particularly true for the case of high deformation rates, where the static recovery and recrystallization can proceed rapidly during a very short holding period after deformation, as shown in Photo. 1. With regard to this point, the newly developed hot deformation equipment used here also appears to be very suitable for investigation of dynamic restoration process.

\section{Conclusion}

The hot deformation behavior of austenite in HSLA 
steels as well as in 18-8 stainless steel was investigated by hot compression testing. The effect of $\mathrm{Nb}$ on the dynamic recrystallization behavior and on the microstructural changes during the dynamic restoration process was primarily studied.

(1) Complete dynamic recrystallization in the HSLA steels took place at temperatures above $1000{ }^{\circ} \mathrm{C}$ with the strain rate less than $10^{-1} \mathrm{~s}^{-1}$ for strain of 0.70 . This corresponds to $Z$ value less than $10^{15} \mathrm{~s}^{-1}$. This observation indicates that dynamic recrystallization will not take place for the strains and strain rates associated with commercial hot rolling processes.

(2) The flow stress increased with an increase of $\mathrm{Nb}$ content for all deformation conditions, and stress and strain at the peak for dynamic recrystallization also increased with $\mathrm{Nb}$ content. At high strain rate these increases appeared to be brought about by solute $\mathrm{Nb}$ atoms rather than dynamic precipitation of $\mathrm{Nb}(\mathrm{CN})$.

(3) An activation energy for dynamic recrystallization of $96 \mathrm{kcal} / \mathrm{mol}$, was estimated on the basis of peak stress measurements and this was almost the same for the HSLA steel with or without $\mathrm{Nb}$ addition and for the 18-8 stainless steel.

(4) Metallographic examination revealed that dynamic recrystallization started at a strain of about $0.8 \times \varepsilon_{p}$, originating by local bulging of grain boundaries. Dynamically recrystallized grains had irregular shaped grain boundaries and contained a substructure consisting of isolated or network-like dislocations.

(5) Refinement of the initial grain size increased the flow stress in the work hardening region, but it did not influence the dynamically recrystallized grain size. Instead, the latter was dependent on the steady state flow stress determined by the deformation conditions. The cyclic hardening and softening flow behavior was associated with refinement of the initial grain size and is thought to be simply due to the accelerating effect of nucleation rate through the increase of nucleation site area with refinement of initial grain size.

(6) The microstructures obtained by dynamic restoration processes showed relatively soft hardness at room temperature. That is, fractional recovery of hardness in dynamic recovery and dynamic recrystallization was approximately 60 and $95 \%$ of that of cold rolling with the same strain of 0.70 in $18-8$ stainless steel.

\section{Acknowledgements}

The authors would like to express their appreciation to Mr. Shiramatsu, Director of Technical Research Center of Nippon Kokan K.K., for permission to publish this paper, and to Dr. P.J. Wray of the
Research Laboratory of U.S. Steel Corp., for his help in correcting the English of this paper.

\section{REFERENCES}

1) G. M. Sellars and W.J. McG. Tegart: Mem. Sci. Rev. Met., 63 (1966), 731.

2) J. J. Jonas, G. M. Sellars and W. J. McG. Tegart: Met. Rev., 14 (1969), 1.

3) C. Rossard: Metaux, (1960), 140.

4) R.A.P. Djaic and J. J. Jonas: JISI, 210 (1972), 256.

5) S. Sakui, T. Sakai and K. Takeishi: Tetsu-to-Hagané, 62 (1976), 70.

6) R. A. Petkovic, M. J. Luton and J. J. Jonas: Proc. Int'l Conf. of The Hot Deformation of Austenite, 1976, AIME, Gleveland, (1977), 68.

7) H. P. Stüwe: Proc. Conf. on Deformation under Hot Working Conditions, 1966, ISI, Sheffield, ISI Pub. No. 108, (1968), 1.

8) M. J. McQueen, R. A. Petkovic, H. Weiss and L. G. Hinton: Proc. Int'l Conf. of The Hot Deformation of Austenite, 1976, AIME, Gleveland, (1977), 113.

9) F. Garofalo: Fundamentals of Creep and Creep Rupture in Metals, Macmillan, New York, (1965).

10) Y. Ohtakara, T. Nakamura and S. Sakui: Trans. ISIJ, 12 (1972), 207.

11) T. Nakamura and M. Ueki: Trans. ISIJ, 15 (1975), 185.

12) G. J. Richardson, G. M. Sellars and W. J. McG. Tegart: Acta Met., 14 (1966), 1225.

13) M.J. Luton and C. M. Sellars: Acta Met., 17 (1969), 1033.

14) J. P. Sah, G. J. Richardson and C. M. Sellars: Metal Sci., 8 (1974), 325.

15) R. Sandström and R. Lagneborg: Script. Met., 9 (1975), 59.

16) R. Sandström and R. Lagneborg: Acta Met., 23 (1975), 387.

17) W. Roberts, H. Boden and B. Ahlblon: Metal Sci., 13 (1979), 195.

18) I. Weiss and J. J. Jonas: Met. Trans. AIME, 11A (1980), 403.

19) M.J. Luton, R. Dorvel and R. A. Petkovic: Met. Trans. AIME, 11 A (1980), 411.

20) I. Weiss and J. J. Jonas: Met. Trans. AIME, 10A (1979), 831.

21) G. M. Sellars: Proc. of Recrystallization and Grain Growth of Multi-phase and Particles Containing Materials, RISO National Lab., Roskilde, Denmark, (1980), 291.

22) S. Yamamoto and G. Ouchi: Trans. ISIJ, 20 (1980), B671.

23) M. G. Akben, I. Weiss and J. J. Jonas: Acta Met., 29 (1981), 111.

24) G. Ouchi and T. Okita: to be published in Trans. ISIJ.

25) I. Kozasu, T. Shimizu and H. Kubota: Trans. ISIJ, 11 (1971), 367.

26) H. J. McQueen and S. Bergerson: Metal Sci. J., 6 (1972), 25.

27) E. L. Brown and A. J. Deardo: Met. Trans. AIME, 12A (1981), 39. 